\title{
Developing Third Grade Boys and Girls' Spatial Ability by Means of an Extra-Curricular Teaching Unit
}

\author{
PATKIN, Dorit ${ }^{*}$ \\ Mathematics Department, Kibbutzim College of Education, 149 Namir Road, \\ Tel-Aviv, Israel; Email: Patkin@ netvision.net.il \\ FADALON, Limore \\ Haim Bar_Lev Elementary School, Petach-Tikva, Israel; Email: limorfad@gmail.com
}

(Received November 11, 2012; Revised June 10, 2013; Accepted June 21, 2013)

\begin{abstract}
The present study focuses on the contribution of a teaching unit to the development of spatial ability of third graders in general and from a gender point of view in particular. The research population consisted of seventy-four pupils: thirty-seven pupils in the experimental group who attended the teaching unit and thirty-seven pupils in the control group. The spatial ability of all the pupils was examined by means of common tests which checked cognitive capabilities of spatial ability. The research findings illustrate an improvement in the spatial ability of the experimental group pupils following the participation in the teaching unit. Moreover, regarding the gender aspect, the findings show that there was no significant differentiation between the spatial ability of third grade boys and the spatial ability of girls of the same age group.
\end{abstract}

Keywords: spatial ability, teaching unit, gender differences, 3D shapes, solid geometry, third grade pupils' spatial ability

MESC Classification: B52, B59, G42, G49

MSC2010 Classification: $97 \mathrm{~B} 50,97 \mathrm{G} 40$

\section{INTRODUCTION}

Our world is basically geometric and, in order to understand and appreciate it, spatial ability is necessary. Gardner (1993) stipulates that spatial intelligence is one of the seven intelligences of the multiple intelligences theory. This theory advocates that the use of spatial intelligence is most crucial for developing mathematical thinking of young children. Piaget \& Inhelder (1967) emphasise the relation between the development of spatial

\footnotetext{
* Corresponding author
} 
ability and the perception of the concept number at young age. After presenting the theoretical background, the study discusses the benefit of using a teaching unit for pupils' spatial development.

\section{THEORETICAL BACKGROUND}

Spatial ability is defined as one of people's important skills and it affects the daily life of each of us. Gardner (1993) based his multiple intelligence theory on two key motives: representations of space which children gradually build through internalisation and organisation of motor activities and progress from stage to state. All this is done in a continuous manner also as a result of biological maturity and, therefore, it can be compared to chronological age. Gardner (1993) argues that the more children develop an ability to perceive space, the more they develop their ability to acknowledge the quantitative value of their environment, linking it to an abstract series of symbols. Children at the age of 8-9 are at the concrete operations stage. Their spatial thinking still depends on recurrent experiences and assignments which require a static spatial ability and it is still limited to concrete situations and events.

In the Curriculum and Evaluation Standards for School Mathematics of the National Council of Teachers of Mathematics (NCTM, 1989, pp. 48-50), teachers are called upon to put more emphasis on developing the sense of space within the framework of mathematics studies already from young age. Moreover, they are requested to pay greater attention to inquiry activities associated with spatial transformations, such as assembling decomposing and changing shapes.

According to Petersen \& Linn (1985), the entirety of spatial ability can be divided into three categories of sub-abilities which, together, constitute the overall spatial ability. These three categories are parallel to different cognitive abilities which encompass people's overall spatial ability: spatial visualisation ability, spatial orientation ability, and mental rotation ability.

Spatial visualisation ability (VS). Tasks which require complex and multi-stage manipulations regarding spatial information. The tasks can require process of mental rotation or spatial orientation.

Spatial orientation ability (SO). The ability to determine spatial relations with consideration of the direction of the object body, while ignoring certain distracting information. The ability to dissolve a picture's elements or misleading clues.

Mental rotation ability (MR). The ability to cope with tasks which are required for find- 
ing an identical model of a 2D or 3D form with maximum speed and rigour.

\section{Common difficulties in solid geometry studies}

Children face difficulties in learning solid geometry. The main reason for these difficulties is the gap between the teaching level and the pupils' learning and comprehension ability. The pupils have a low geometric thinking level while the teachers are trying to deliver knowledge on a thinking level which is higher than the pupils' level (Patkin, 2010). Additional difficulties are inability to make a manipulation of body photos (BenHaim, Lappan \& Houang, 1989) as well as the inability to interpret 3D shapes and draw them (Koester, 2003).

An example of such a gap was shown by Battista \& Clements (1998). They reported that elementary school pupils found it considerably difficult to find the number of cubes in 3D structures with rectangular sides. The pupils had difficulties to count the number of cubes in certain structures, because they were unable to coordinate different "orthogonal views" of the same cube buildings. An orthogonal view is a view whereby only one side of the structure is seen. In order to coordinate these views, one has to decompose the upper part of the structure into the cubes composing it. The same thing should be done also with the front of the structure, determining the spatial relation between the two views. Battista \& Clements (1998) described four mental models of cube buildings in which pupils sometimes are wrong when counting the cubes composing those structures. For example, viewing the structure as an unstructured collection of cubes, viewing the structures only in terms of sides, viewing the structures as a filling of a space located "at the centre" of the structure and viewing the structures in terms of layers. Battista \& Clements (1998) attribute great importance to the development of counting strategies by means of suitable learning assignments. This development facilitates construction of the cognitive framework required for understanding the measurement of volume and formulae of volume definition. This is corroborated by the study of Patkin \& Dayan (2013), who found that the use of a teaching unit at the 12th grade, improved the pupils' spatial visualisation.

\section{The contribution of teaching units of spatial visualisation}

The literature describes research findings, which show that spatial visualisation can be improved by using teaching units comprising practice and teaching in this discipline. Patkin \& Dayan (2013) investigated a case study of one class versus a control group. Their study focused on the impact of a teaching unit, which is not part of the regular curriculum, on the improvement of spatial ability of high school pupils (forty-six 12thgraders, aged 17-18, both boys and girls) in general as well as from a gender perspective. The study explored three sub-abilities: mental rotation (MR), spatial visualisation (VS) 
and spatial orientation (SO). Findings indicated that the spatial orientation of the experimental group pupils had considerably improved. The findings also illustrated a significant gender-based advantage in favour of the boys in some of the spatial abilities even before the implementation of the teaching unit. The hypothesis relating to the reduction of the gender differences was not corroborated.

Sorby (2009) reports the results of a pilot study which was conducted using multimedia software and workbook with middle and high school pupils (grades 7-10, ages 12-15). The software and workbook materials were effective in improving the 3D spatial skills of the middle school pupils who participated in the study as well as the group of high school geometry pupils.

Another computer-aided exercise is the solution of 2D puzzles. A study investigating pupils' spatial visualisation improvement after using such an exercise illustrated a considerable improvement in the attainments of pupils (aged 18 in average) who actively and interactively practiced the solution of the puzzles, rather than just as observers. Pupils who attended the programme and observed another pupil solving the puzzle did not improve their attainments. The conclusion derived from the study was that interaction with the computer is essential for improving one's achievements (Smith, 2001, pp. 1755-1760).

Dixon (1997) investigated how the use of computerised practice affected eighthgraders, when using geometrical drawing software as an integral part of the learning process. He found a significant improvement in tests of mental rotation manifested by the attainments of those pupils who used the computer versus those who did not engage in computerised practice at all.

\section{Tests of spatial visualisation}

Tests designed to measure spatial visualisation, focus on the three areas and cognitive capabilities according to Linn \& Petersen (1985). The acceptable tests for measuring mental rotation ability were designed by Shepard \& Metzler (1971). This type of mental assignments are considered as the most reliable index for assessing spatial intelligence, since they cannot be effectively solved by means of "words". The Shepard \& Metzler tests and their different versions have been tried over the years and were proven as valid tests for measuring the cognitive aspect of spatial ability (Colom, Contreras, Botella \& Santacreu, 2001).

Tests classified as spatial orientation tests are in the style of "how many cubes are needed to build a certain model". This assignment does not specifically include counting or estimating cubes in structures but rather assignments which require the use of spatial orientation and spatial visualisation as such drawing and isometrics. Tests of visual ability include unfolding of solids - 3D shapes. 


\section{Gender differences in spatial ability}

Spatial ability skills constitute one of the subjects in which studies found a considerable and significant differentiation between boys and girls, in favour of boys (Spelke, 2005).

Studies show a gender difference in spatial visualisation at various ages and in various cultures (Medina, Gerson, \& Sorby 1998), clearly endowing boys with better spatial ability than girls (Caplan, Crawford, Hyde \& Richardson, 1997; Carpenter, 2003; Halpern, 2005). Moreover, this gap is not only the outcome of environment, education or stereotypes but it is also congenital (Gur, Alsop, Glahn, Petty, Swanson \& Maldjian, 2000; Pinker \& Spelke, 2005). Studies such as the one conducted by Gur et al. (2000) illustrate that, in general, there are distinct differences in brain activity between men and women as well as in anything connected with spatial orientation thinking. Findings indicate that in the case of women, activity was registered in the right side of the brain while coping with spatial visualisation problems. Conversely, men activated both the right and left side of the brain. The study shows that using only one side of the brain constitutes a reason for the difference in men and women's spatial orientation performance. The study corroborates similar previous studies, supporting the arguments that there is a gender difference in spatial orientation also in the behavioral and neurological aspect (Gur et al., 2000).

A review by Maccoby \& Jacklin (1974) illustrates the advantage of boys over girls in the performance of a wide variety of space-oriented tests. The researchers concluded that gender differences in the field of space emerge for the first time close to adolescence and become stable at adulthood.

It is important to point out that, according to the research literature, there are gender differences in all three test types and the gap between men and women is not uniform in all the tests. The most distinct difference is expected in the spatial rotation tests, which measure mental rotation. The smallest difference is expected in the visualisation tests, which examine visual ability of unfolding solids (3D shapes) (Halpern, 2005; Linn \& Peterson, 1985). In their study, Patkin \& Dayan (2013) found also a significant advantage of boys in mental rotation and visualisation ability.

Conversely, Haciomeroglu \& Chicken (2012) conducted a study which examined calculus pupils' mathematical performances and preferences for visual or analytic thinking regarding derivative and anti-derivative tasks presented graphically. The results indicated that pupils' visual preferences were not influenced by gender.

Another interesting finding indicates a gender difference, namely the percentage of women who fail in pre-tests and are referred to preparatory courses designed to improve spatial visualisation is considerably higher than that of men (Sorby \& Baartmans, 2000).

To sum up, we assume that spatial ability, which constitutes a basic layer in pupils' 
success in mathematics-oriented disciplines, can probably be improved by means of a teaching unit.

\section{RESEARCH}

\section{Research objectives}

The present study explored whether an extra-curricular teaching unit can enhance spatial ability development of third grade boys and girls.

\section{Research questions}

(1) To what extent are there differences in spatial ability of pupils who have attended the extra-curricular teaching unit and pupils who have not studied it in general and in each of the three components of spatial ability: mental rotation, spatial visualisation and spatial orientation?

(2) To what extent has the spatial ability improvement of the experimental group pupils in each of the three components - mental rotation, spatial visualisation and spatial orientation - persisted also a month following the end of the experiment?

(3) Are there differences in spatial ability between boys and girls in the experimental group prior to the teaching unit and following it?

\section{METHODOLOGY}

\section{Research population}

Seventy-four pupils aged 8-9 in two parallel third grade classes with similar attainments (average and above). The experimental class consisted of thirty-seven pupils: sixteen girls and twenty-one boys. The control class consisted of thirty-seven pupils: fifteen girls and twenty-two boys. Both classes studied in the previous academic year (2nd grade) the subject of solids according to the curriculum. In this framework they learnt to identify solids (3D shapes) by viewing them and then to name them. The control group was designed to ascertain that the experimental effect was clearly and unequivocally caused by the teaching intervention.

\section{Research procedure}

The study was conducted during a period of nine weeks, as follows: 
2.1. The first part of the study (week 1) consisted of a pre-test, given to all the pupils from the two groups. The test comprised all the three cognitive areas of spatial visualisation. The questions were taken from question and test databases for checking the three spatial sub-abilities. These questions and tests were found to be appropriate for these purposes (Shepard \& Metzler 1971; Ben-Him, Lappan \& Houang1989; Patkin \& Dayan, 2013).

Part one of the test - Spatial Orientation (SO) - 10 open-ended questions. Pupils had to count cubes in an isometric 3D shape, indicating their number. For example:
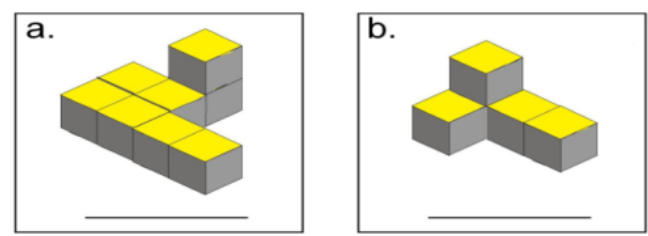

Figure 1. Item from the test: How many cubes are there in the figure?

Part two of the test - Spatial Visualisation ability (VS) - was based on projections of 3D solids (3D shapes). The test comprised 10 questions, starting from easy questions to difficult ones. Pupils had to choose out of five options the projection matching the body. For example:

1. You have to find the projection from the right

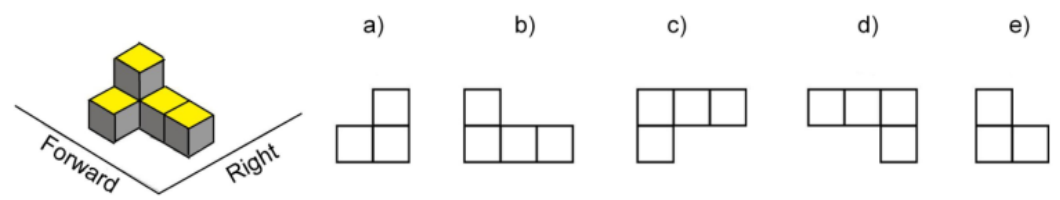

2. You have to find the projection from the front

a) b) c)

e)
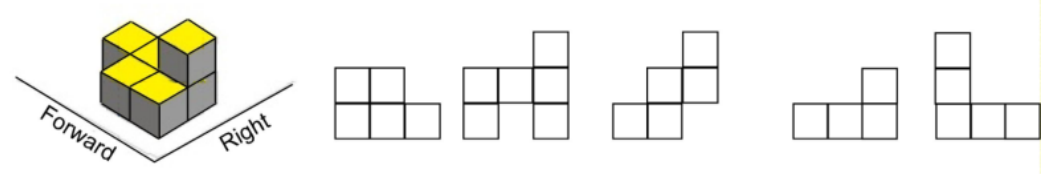

Figure 2. What is the projection of the appropriate body?

Part three of the test - Mental Rotation (MR) - comprised ten questions, starting from easy questions to difficult ones. Pupils had to identify out of five options the body matching the original shape. For example: 
a)

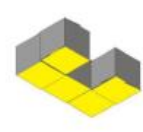

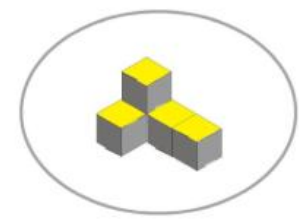

b) d)

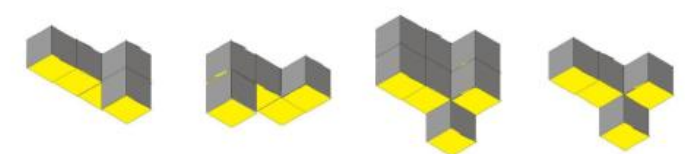

Figure 3. Which body matches the circled shape?

2.2. The second part of the study (weeks 2-4) was dedicated to the teaching unit. This unit was grounded on the principles of the teaching unit and methodology presented in the study by Sorby \& Baarmans (2000), as well as on a learning unitbook for spatial visualisation development (Sorby, Wysocki \& Baartmans, 2002), combined with artistic elements for developing the pupils' visual challenge. While the experimental group pupils participated in the teaching unit, the control group pupils studied subjects included in the regular curriculum (and not solid geometry).

2.3. The third part of the study (week 5) included a post-test, given to the pupils from both groups. The post-test was identical to the pre-test, namely the questions were the same. We thought that the participants were unable to remember answers from the first test.

2.4. The forth part of the study (week 9) included retention test, given to the pupils from the experimental group only. It was identical to the pre test. It is important to point out that in the course of the three weeks between the 6th and the 9th weeks, the pupils did not study and were not exposed to exercises and problems associated with spatial ability.

\section{Research method and data analysis}

This study used quantitative methods. The questions were found to be appropriate for these purposes (Shepard \& Metzler 1971; Ben-Haim, Lappan, \& Houang1989; Patkin \& Dayan, 2013). The test reliability was Cronbach's analysis. The reliability coefficient based on data collected in this test was Cronbach's $\alpha=0.85$.

\section{Ethical considerations}

Permission to conduct the study was granted by the school. The pupils gave their con- 
sent to participate in the study. The aims and objectives of the study were discussed with them. Their names were not divulged. The exams were stored away safely by the authors.

\section{The teaching unit}

The teaching unit comprised a series of three 1.5-hour long sessions. Each session was divided into three stages: the challenge stage, the inculcation stage and the exercising stage.

\subsection{The challenge stage.}

Challenges, which included optical illusion, were presented to the pupils in order to evoke interest and inquisitiveness. For example:

In the challenge activity of the first lesson, Figure 4 was presented to the pupils and they were required to examine the number of cubes in the picture.

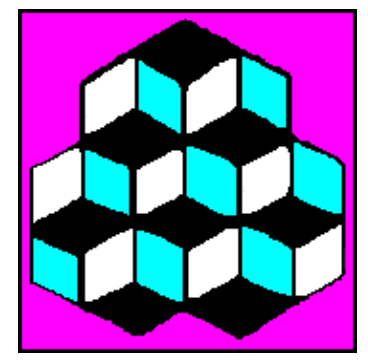

Figure 4. Optical illusions

\subsection{The inculcation stage}

During the first session, pupils were requested to count cubes in a structure photo by means of a presentation. Moreover, they were required to experience building a model of the presented structure. For example: 


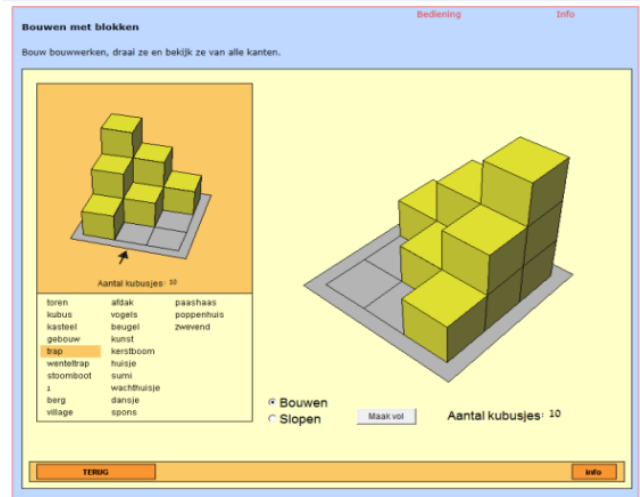

Figure 5. Building a model of a structure ${ }^{1}$

In the second session, the pupils experienced with a view of cube buildings from different directions, namely from a body and shifting from viewing a body from three views to building a cube building. For example:

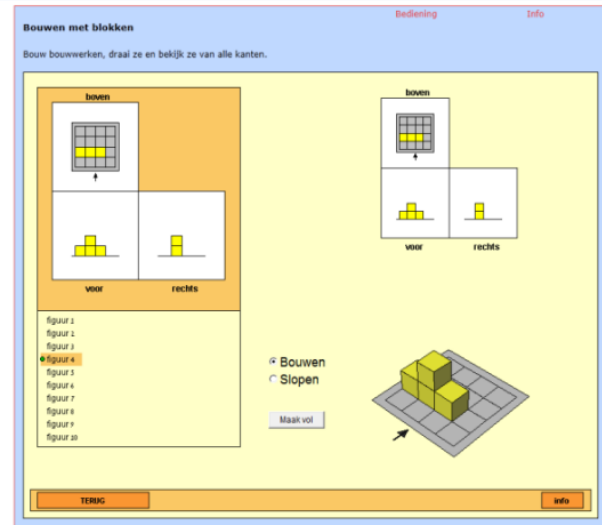

Figure 6. From viewing a body from three views to building a cube building ${ }^{2}$

In the third session, the pupils experienced with a correct perception of a $2 \mathrm{D}$ drawing which describes a 3D body. For example:

$\begin{array}{ll}1 & \text { http://www.fi.uu.nl/toepassingen/00339/toepassing_wisweb.html } \\ 2 & \text { http://www.fi.uu.nl/toepassingen/00339/toepassing_wisweb.html }\end{array}$ 


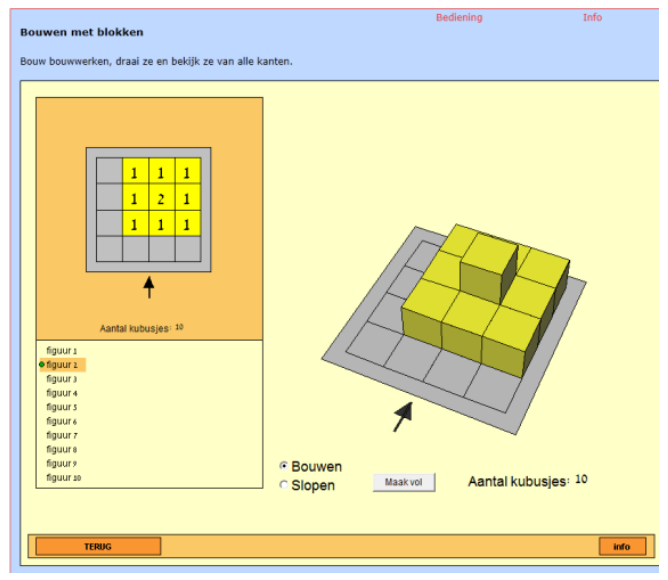

Figure 7. A correct perception of a 2D drawing which describes a $3 \mathrm{D}$ body $^{3}$

\subsection{The exercising stage}

At this stage, the pupils were given an exercise assignment on the subject of spatial ability development. They interacted with other pupils and built cube buildings distributed to them.

5.3.1. An exercising example from Session 1: representing a cube building by drawing on a coded page.

\section{Part I - From 3D to coded plane drawing.}

Please build each of the drawn structures and draw its matching map. For example:
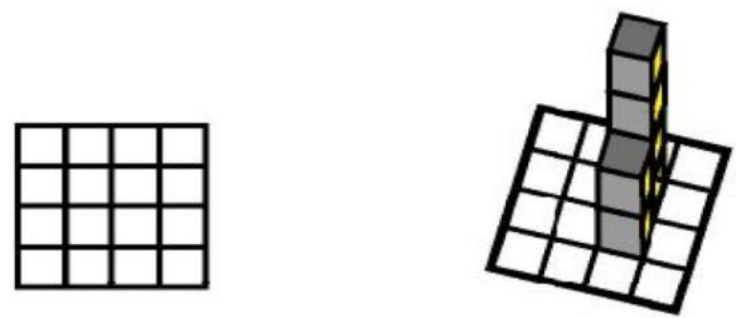

Figure 8. Build the drawn structure and draw its matching map

\section{Part II - From a coded plane to a 3D structure.}

Please build the structure by using cubes. For example:

3 http://www.fi.uu.nl/toepassingen/00339/toepassing_wisweb.html 


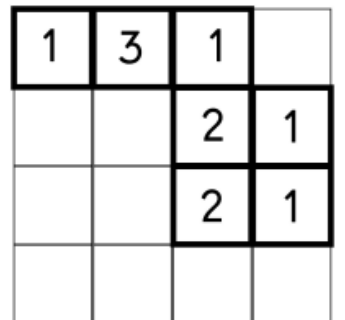

Figure 9. From a coded plane to a 3D structure

5.3.2. An exercising example from Session 2: a view of cube buildings from different views.

\section{Part I - From a structure to projections.}

Below are 3D shapes. Please build every solid by using cubes and make a drawing of the body from two directions. For example:

a.
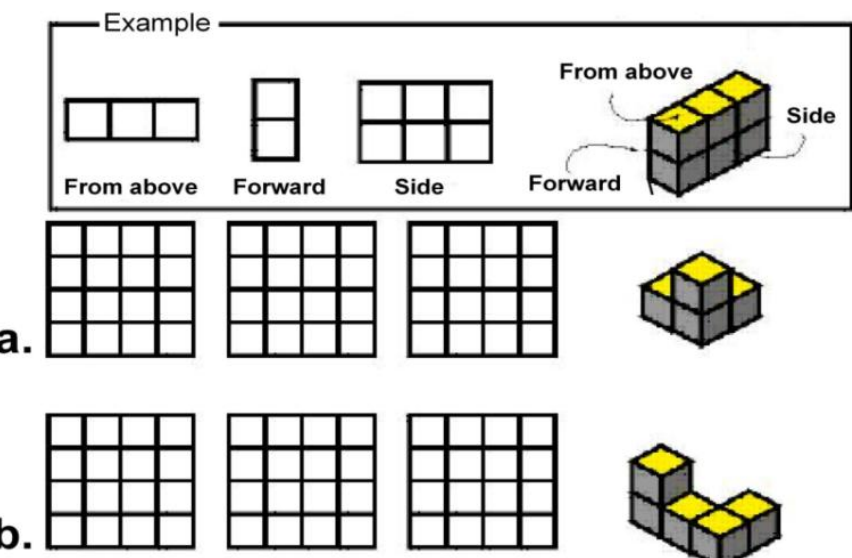

Figure 10. From a structure to projections

\section{Part II - From a drawing to a 3D structure}

1. Look at the three views.

2. Estimate the number of cubes required for building the body.

3. Build the body and verify your estimate.

4. Check whether the body which you have built matches its three views.

For example: 


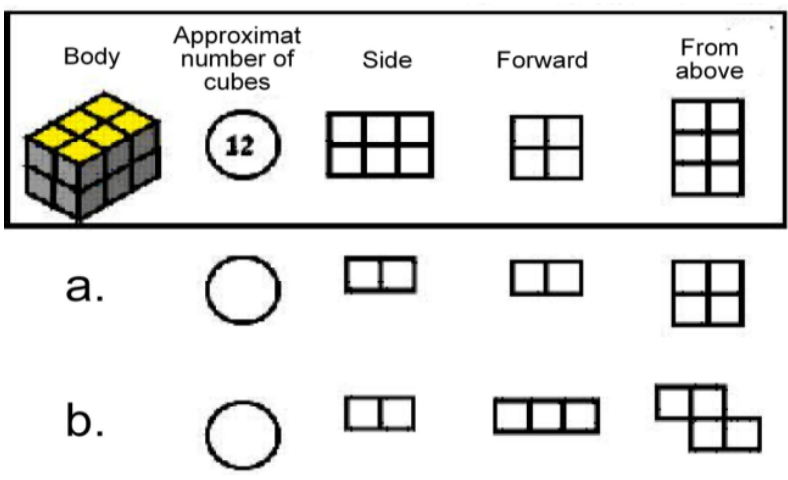

Figure 11. From a drawing to a 3D structure

\subsubsection{An exercising example from Session 3: a view of cube buildings from different directions.}

Part I - Finding identical structures by means of concrete structures.

1. Build by using cubes the following structures: For example:

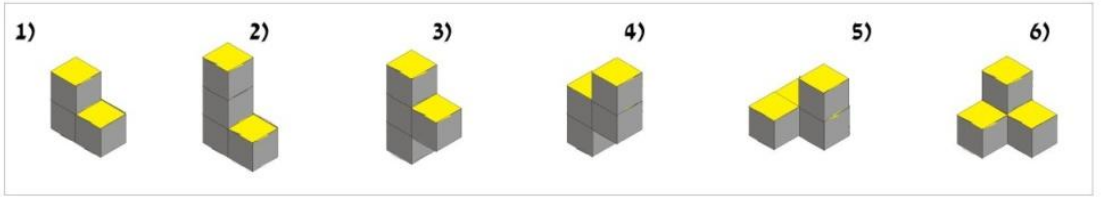

Figure 12. Finding identical structures by means of concrete structures

2. The following drawings also describe the structures which you have built.

Match the number of the structure above with the letter written next to the structure below which describes the same structure. For example:

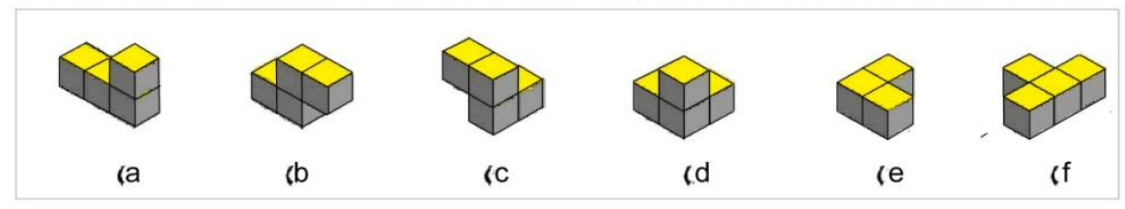

Figure 13. Match the structure

\section{Part II - Finding identical structures in a coded drawing.}

Build each structure by using cubes and place each structure according to the drawing. For example: 
a)

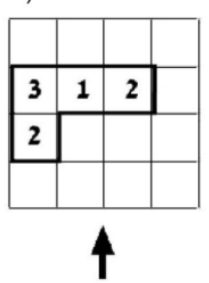

b)

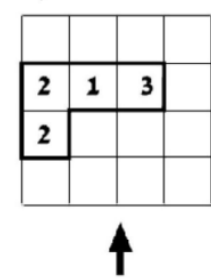

c)

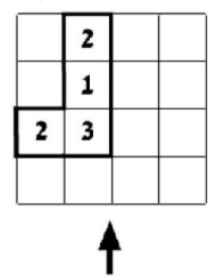

d)

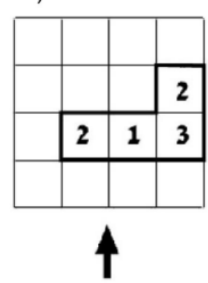

Figure 14. Finding identical structure in a coded drawing

Rotate the structures and check whether there are identical structures among the structures which you have built. If there are such structures, make a rotation so that it is easy to see which the identical structures are.

\section{FINDINGS}

The first research question relates to differences in spatial ability of pupils who have attended the extra-curricular teaching unit and pupils who have not. This was checked by a comparison of the scores in each part of the test and by the total means scores of pupils in the two groups prior to the experiment and immediately following it.

Table 1. Mean scores and standard deviations in the tests $\left(\mathrm{p}<0.05^{*}\right)$

\begin{tabular}{|c|c|c|c|c|c|c|c|c|c|c|}
\hline \multirow{3}{*}{$\begin{array}{c}\text { Test } \\
\text { compo- } \\
\text { nent }\end{array}$} & \multirow{3}{*}{$\mathrm{t}(\mathrm{p})$} & \multicolumn{4}{|c|}{ Experimental group $(n=37)$} & \multirow{3}{*}{$\mathrm{t}(\mathrm{p})$} & \multicolumn{4}{|c|}{ Control group $(n=37)$} \\
\hline & & \multicolumn{2}{|c|}{ Pre-test } & \multicolumn{2}{|c|}{ Post-test } & & \multicolumn{2}{|c|}{ Pre-test } & \multicolumn{2}{|c|}{ Post-test } \\
\hline & & $\begin{array}{l}\text { Mean } \\
\text { score }\end{array}$ & S.D. & $\begin{array}{l}\text { Mean } \\
\text { score }\end{array}$ & S.D. & & $\begin{array}{l}\text { Mean } \\
\text { score }\end{array}$ & S.D. & $\begin{array}{l}\text { Mean } \\
\text { score }\end{array}$ & S.D. \\
\hline \begin{tabular}{c}
\multicolumn{1}{c}{ VS } \\
(Spatial \\
Visuali- \\
sation) \\
\end{tabular} & $6.26 *$ & 3.14 & 1.53 & 5.30 & 2.32 & 2.8 & 2.92 & 1.82 & 3.68 & 2.00 \\
\hline $\begin{array}{c}\text { SO } \\
\text { (Spatial } \\
\text { Orienta- } \\
\text { tion) }\end{array}$ & $6.94 *$ & 4.92 & 2.94 & 8.32 & 1.31 & 3.16 & 4.38 & 2.14 & 5.95 & 2.22 \\
\hline $\begin{array}{c}\text { MR } \\
\text { (Mental } \\
\text { Rota- } \\
\text { tion) } \\
\end{array}$ & $3.38 *$ & 7.16 & 1.64 & 7.98 & 1.94 & 1.5 & 7.03 & 2.10 & 7.65 & 1.74 \\
\hline $\begin{array}{l}\text { Total } \\
\text { mean } \\
\text { score }\end{array}$ & $5.53 *$ & 5.07 & 2.04 & 7.20 & 1.86 & 2.5 & 4.78 & 2.02 & 5.76 & 1.99 \\
\hline
\end{tabular}


The findings illustrate that, prior to the experiment; the composition (i.e., pupil profiles, attainments) of both groups was similar. In the experimental group, the mean score in the pre-test was 5.07 and in the control group it was 4.78. On the other hand, following the experiment and the teaching unit, there was a significant improvement in the experimental groups' attainments -7.2 (after weighing the three test components together) versus those of the control group -5.76 .

The difference between the experimental group and the control group in the visual ability - VS-tests has increased following the teaching unit (a difference of 0.22 in the pre-test mean score, 3.14 compared to 2.92 and a difference of 1.62 in the post-test mean scores, 5.30 compared to 3.68). The same applied also to spatial orientation - SO-tests. The difference has increased following the teaching unit (a difference of 0.54 in the pretest mean scores, 4.92 compared to 4.38 and a difference of 2.37 in the post-test mean scores, 8.32 compared to 5.95). On the other hand, in the mental rotation - MR-tests, the difference in mean scores between the pre-test $(0.13 ; 7.16$ compared to 7.03$)$ and the post-test $(0.33 ; 7.98$ compared to 7.65$)$ is negligible.

The second research question aimed to explore whether spatial ability improvement of the experimental group pupils in each of the three components - mental rotation, spatial visualisation and spatial orientation - persisted also a month following the end of the experiment.

The findings show that in each of the spatial ability components the improvement persisted also a month after the experiment. T-tests indicate that the achievements were maintained one month later in all the components, the findings indicating no statistically significant differences between the two tests -7.20 immediately after the experiment and 7.26 a month later. Nevertheless, a comparison of the mental rotation component in the test, an improvement and further increase in knowledge were manifested a month after the experiment (immediately after the experiment -7.98 and a month later -8.35 ).

The questions were arranged in an ascending order of difficulty from the easy to more difficult ones. However, it is worthwhile noting that, based on the findings, there were easy questions which the pupils had difficulty to answer while there were more difficult questions which they answered more easily (cf. Table 2).

The third research question focused on the differences in spatial ability between boys and girls in the experimental group prior to the teaching unit and following it (cf. Table 3). 
Table 2. Mean scores and standard deviations in the tests immediately after the teaching unit and a month later $\left(\mathrm{p}<0.05^{*}\right)$

\begin{tabular}{|c|c|c|c|c|c|}
\hline \multirow{2}{*}{ Test component } & \multicolumn{5}{|c|}{ Experimental group $(n=37)$} \\
\cline { 2 - 6 } & \multicolumn{2}{|c|}{ Post-test } & \multicolumn{2}{c|}{ Retention test } & \\
\cline { 2 - 6 } & $\begin{array}{c}\text { Mean } \\
\text { score }\end{array}$ & S.D. & $\begin{array}{c}\text { Mean } \\
\text { score }\end{array}$ & S.D. & $\mathrm{t}(\mathrm{p})$ \\
\hline VS (Spatial Visualisation) & 5.30 & 2.32 & 5.19 & 2.77 & 0.395 \\
\hline SO (Spatial Orientation) & 8.32 & 1.31 & 8.24 & 1.72 & 0.338 \\
\hline MR (Mental Rotation) & 7.98 & 1.94 & 8.36 & 1.80 & $2.30^{*}$ \\
\hline Total mean score & 7.20 & 1.86 & 7.26 & 2.10 & 0.25 \\
\hline
\end{tabular}

Table 3. Mean scores and standard deviations obtained in the tests by the boys and by the girls.

\begin{tabular}{|c|c|c|c|c|c|c|c|c|}
\hline & \multicolumn{4}{|c|}{ Girls $(n=16)$} & \multicolumn{4}{c|}{ Boys $(n=21)$} \\
\cline { 2 - 10 } Test component & \multicolumn{2}{|c|}{ Pre-test } & \multicolumn{2}{c|}{ Post-test } & \multicolumn{2}{c|}{ Pre-test } & \multicolumn{2}{c|}{ Post-test } \\
\cline { 2 - 9 } & $\begin{array}{c}\text { Mean } \\
\text { Score }\end{array}$ & S.D. & $\begin{array}{c}\text { Mean } \\
\text { score }\end{array}$ & S.D. & $\begin{array}{c}\text { Mean } \\
\text { score }\end{array}$ & S.D. & $\begin{array}{c}\text { Mean } \\
\text { score }\end{array}$ & S.D. \\
\hline $\begin{array}{c}\text { VS (Spatial } \\
\text { Visualisation) }\end{array}$ & 3.13 & 1.30 & 4.00 & 1.13 & 2.77 & 2.11 & 3.46 & 2.42 \\
\hline $\begin{array}{c}\text { SO (Spatial } \\
\text { Orientation) }\end{array}$ & 3.93 & 1.94 & 5.13 & 1.77 & 5.46 & 2.09 & 6.50 & 2.37 \\
\hline $\begin{array}{c}\text { MR (Mental } \\
\text { Rotation) }\end{array}$ & 7.00 & 1.89 & 7.27 & 1.58 & 7.05 & 2.28 & 7.91 & 1.82 \\
\hline $\begin{array}{c}\text { Weighted mean } \\
\text { score }\end{array}$ & 4.69 & 1.71 & 5.47 & 1.49 & 5.09 & 2.16 & 5.96 & 2.20 \\
\hline
\end{tabular}

A comparison of the total mean scores obtained by boys (5.09) and by the girls (4.69), as well as an examination of the test components prior to the experiment before studying the subject, yielded similar attainments. The boys had an advantage in spatial orientation (SO) and mental rotation (MR) whereas girls demonstrated an advantage in spatial visualisation (VS). Upon completion of the teaching unit, both sub-groups showed an improvement in all test components: boys -5.96 and girls -5.47 . The gap between boys and girls was still in favour of the boys in spatial orientation and mental rotation and in favour of the girls in spatial visualisation. However, the differences were not significant.

\section{DISCUSSION AND CONCLUSIONS}

The present study explored the contribution of an extra-curricular teaching unit to the 
development of spatial ability of third grade boys and girls. Using spatial intelligence is extremely important for the development of mathematical thinking, particularly in young children (Gardner, 1993, pp. 170-204). The findings show that attainments of all the experimental group pupils after attending the teaching unit were higher than those of the control group pupils. These attainments could be attributed to the impact of the teaching unit.

This conclusion is in line with researchers (Koester, 2003; Patkin, 2010; Patkin \& Dayan, 2013) who found that the development of geometric thinking is more teachingdependent than age-dependent. Moreover, Ben-Haim, Lappan \& Houang (1989) stipulate that using a teaching unit enhances pupils' spatial visualisation. In the present study, prior to the teaching unit, the pupils encountered difficulties in understanding a cube building as well as the shifting and rotation thereof. Only after completing the teaching unit which used both illustration aids and computer programmes, has their spatial visualisation improved.

The improvement was manifested only in the first two categories of spatial ability (VS and SO) and not in the third one (MR). This might be due to the fact that spatial visualisation and spatial orientation are simpler and the pupils are more exposed to it outside the school framework, during their leisure time, through board games and computer games. Furthermore, in their daily life, they frequently come across many examples associated with these categories.

The third category is complicated and need more extensive practice and experience than the two others. Mental rotation necessitates maximum response time and accuracy. Hence, pupils are required to invest time, practice and assimilate the material. Perhaps in order to perform better, as indicated above, practice in these topics should be expanded and enhanced while teaching the subject.

The biggest change found in the present study is in line with the study of Battista \& Clements (1998). They argued that spatial ability improvement is grounded on the use of mental models of cube buildings. Further findings of the present study discussed spatial ability and its components among boys and girls before and after the experiment. As already mentioned, no significant differences in spatial ability were found between boys and girls before and after the experiment. The comparisons of the total mean scores, yielded similar attainments. This finding corroborates the review of Maccoby \& Jacklin (1974), who maintain that there are no significant gender differences in spatial ability at young age, like that of the present research participants (age 8-9). The differences appear for the first time near to the age of adolescence and get stabilised at adulthood. This contradicts the professional literature indicating gender differences in spatial ability (BenHaim, Lappan \& Houang, 1989; Spelke, 2005; Patkin \& Dayan, 2013). These differences are manifested at various ages and the results do no change considerably with age. The 
gap is in favour of boys in the three sub-abilities comprising spatial ability: spatial orientation, spatial visualisation and mental rotation.

Maybe if the teaching unit had lasted longer and the research sample had been bigger, significant differences between the genders would have been obtained and the results would have matched the findings of these studies. Nevertheless, using the teaching unit might have prevented gender-oriented gaps in this field.

To sum up, the overall conclusion is that the teaching unit enhanced pupils' spatial ability with its three components.

\section{RESEARCH LIMITATIONS AND RECOMMENDATIONS}

The present study was conducted with a small number of participants, over a short period of time and it engaged only in a particular topic. Hence, it is recommended adopting this approach when coping with a bigger sample as well as expanding the scope of the teaching unit in order to cover additional problems of solid geometry.

Furthermore, it is recommended extending the teaching unit over a longer period of time for the purpose of checking whether the time element has an effect on spatial ability improvement and on the absence of gender differences in this field. It is recommended implementing the teaching unit also for higher grade pupils. This would allow examining whether the use of cube buildings for constructing models, practicing and developing 2D drawing skills for describing 3D shapes are beneficial to higher grade pupils and whether there is no gender differences in this field among these pupils.

\section{REFERENCES}

Battista, M. \&. Clements, D. H. (1998). Finding the number of cubes in rectangular cube buildings. Teach. Child. Math. 4(5), 258-264. ME 1998f.04242

Ben-Chaim, D., Lappan, G. \& Houang, R. T. (1989). Adolescents' ability to communicate spatial information: Analyzing and effecting pupils' performance. Educ. Stud. Math 20(2), 121-146. ME 1990e.02958

Caplan, P.; Crawford, M.; Hyde, J. \& Richardson, J. T. (1997). Gender Differences in Human Cognition. Counterpoints: Cognition, Memory, and Language Series. New York: Oxford University Press. ERIC ED437187

Carpenter, M. (2003). Why girls score low on SATs baffling. Pittsburgh Post-Gazette. 2003(Aug. 27)

Colom, R.; Contreras, M. J.; Botella, J. \& Santacreu, J. (2001). Vehicles of spatial ability. Person- 
ality and Individual Differences 32(5), 903-912.

http://www.uam.es/proyectosinv/psimasd/vehicles.pdf

Dixon, J. K. (1997). Computer use and visualization in pupils' construction of reflection and rotation concepts, School Science and Mathematics 97(7), 352-358. ERIC EJ588583

Gardner, H. (1993). Frames of Mind: The theory of multiple intelligences. New York: Basic Books.

Gur, R.; Alsop, D.; Glahn, D.; Petty, R.; Swanson, C.; Maldjian, J.; Turetsky, B.; Detre, J. \& Gee, J. (2000). An fMRI study of sex differences in regional activation to a verbal and a spatial task. Brain and Language 74(2), 157-170.

Haciomeroglu, E. S. \& Chicken, E. (2012). Visual thinking and gender differences in high school calculus. Int. J. Math. Educ. Sci. Technol. 43(3), 303-313. ME 2012c.00197 http://dx.doi.org/10.1080/0020739X.2011.618550

Halpern, F. D. (2005). Sex, Brains \& Hands - Gender Differences in Cognitive Abilities. Skeptic 2(3), 96-103.

Koester, B. A. (2003). Prisms and pyramids: constructing three-dimentional models to build understanding. Teach. Child. Math. 9(8), 436-442. ME 2003f.05035 ERIC EJ668838

Linn, M. C. \& Petersen, A. C. (1985). Emergence and characterization of sex differences in spatial ability: A meta-analysis. Child Development 56(6), 1479-1498. ERIC EJ328551

Maccoby, E. E. \& Jacklin, C. N. (1974). The psychology of sex differences. Stanford, CA: Stanford University Press.

Medina, A. C.; Gerson, H. B. P. \& Sorby, S. A. (1998). Identifying gender differences in the 3D visualization skills of engineering pupils in Brazil and in the United States. In: Proceedings of the Proceedings of the International Conference for Engineering Education, Rio de Janeiro, Brazil. ERIC ED443729

National Council of Teachers of Mathematics (NCTM) (1989). Curriculum and Evaluation Standards for School Mathematics. Reston, VA: NCTM. ME 1989k.00892

Patkin, D. (2010). The role of "personal knowledge" in solid geometry among primary school mathematics teachers. J. Korea Soc. Math. Educ. Ser. D 14(4), 263-279.

Patkin, D. \& Dayan, E. (2013). The intelligence of observation improving high school pupils' spatial ability by means of intervention units. Int. J. Math. Educ. Sci. Technol. 44(2), 179-195. ME 2013c.00191 http://dx.doi.org/10.1080/0020739X.2012.703335

Piaget, J. \& Inhelder, B. (1967). The child's conception of space. New York: The North Library. ERIC ED034694

Shepard, R. N. \& Metzler, J. (1971). Mental rotation of three-dimensional objects. Science 171, 701-703.

Smith, G. (2001). Interaction Evokes Reflection: Learning Efficiency in Spatial Visualization. In: Proceedings of World Conference on Educational Multimedia, Hypermedia and Telecommunications 2001. 
Sorby, S. A. (2009). Educational research in developing 3-D spatial skills for engineering pupils. International Journal of Science Education 31(3), 459-480. ERIC EJ828856

Sorby, S. A. \& Baartmans, B. G. (2000). The development and assessment of a course for enhancing the 3-D spatial visualization skills of first year engineering students. Journal of Engineering Education 89(3), 301-307

Sorby, S. A., Wysocki, A. F., \& Baartmans, B. G. (2002). Introduction to 3D Spatial Visualization. New York: Cengage Learning

Spelke, E. S. (2005). Sex differences in intrinsic aptitude for mathematics and science: a critical review. American Psychologist 60(9), 950-958. ERIC EJ733610 